\title{
Impact of New Smoking Trends on Women's Occupational Health ${ }^{1}$
}

\author{
Margaret H. Mushinski and Steven D. Stellman \\ Division of Epidemiology, and Division of Biostatistics, American Health Foundation, \\ 320 E. 43rd Street, New York. New York 10017
}

\begin{abstract}
Health problems and needs of females, particularly of working women, are discussed in relation to cigarette smoking and its effects. Problems encountered by working women with regard to understanding and knowledge of health risks are examined, as well as specific diseases and occupations presenting major health problems to the female worker. Smoking is shown to exert effects on females similar to those it exerts on males with regard to those cancers which are generally related to tobacco use. Various occupational exposures such as exposure to asbestos, known to act in synergism with tobacco as a carcinogen, are presented as hazards to the working woman. The cancer-promoting effect of alcohol, in conjunction with smoking, is also mentioned. Heart disease is another health problem which will be confronted by both the working and/or smoking woman, as it is by males. In addition, other occupations formerly thought of as "benevolent," such as office work, are shown to present health hazards. It is concluded that more and greater health hazards will be faced by women, especially as they smoke more and take on more jobs that were traditionally filled by men. Closer monitoring and assessing of health status of women in the work force is called for to ensure that conditions in the workplace are not detriments to good health. Epidemiologic variables suggested for inclusion in future occupational health studies are presented.
\end{abstract}

\section{INTRODUCTION}

The working woman plays a major part in all aspects of the labor force, and her role is expanding. As women increasingly face workplace health hazards heretofore associated with men, investigations of occupational exposures will begin to include data relevant to women. In addition to this expanded focus, recognition of the importance of data on the independent and/or synergistic part played by lifestyle variables in work-related diseases will increase. A major variable to be considered is the use of tobacco products, particularly cigarettes. This much-neglected issue is of great importance in properly evaluating occupational health hazards in order to establish guidelines and safety standards for all workplaces. As new products and chemicals are produced, the potential for unknown hazardous reactions and interactions between such agents and tobacco smoke is increased. This possibility underscores the importance of measuring smoking habits in working populations when assessing risk associated with a particular occupation.

\footnotetext{
1 This work was supported in part by National Cancer Institute Contract No. I-CP-55666 and Grant CA-17613. Computations were performed in part at the Energy Research and Development Administration Mathematics and Computing Laboratory, Courant Institute for Mathematical Sciences, supported by Energy Reserve and Development Administration Contract E(11-1) - 3077 at New York University, New York, N.Y.
} 


\section{THE PROBLEM}

The adverse effects of smoking on men and women are well-known and have been thoroughly reviewed $(19,56,57)$. The major diseases for which cigarette smoking is a causative factor include coronary heart disease (CHD), chronic obstructive pulmonary disease, and cancers of the lung, upper alimentary tract, bladder, pancreas, and larynx. Many of these diseases, however, are also caused by occupational exposure to exogenous agents, such as coke oven emissions, asbestos, or $\beta$-naphthylamine. It is difficult, at best, to determine for an individual in a high-risk occupation who develops one of these diseases and who also smokes, whether the underlying cause of disease was the smoking, the workrelated exposure, or both.

Evidence that tobacco smoke can exacerbate the carcinogenic effect of exposure to industrial agents has recently been reviewed in this journal and elsewhere $(14,15)$. The most widely studied occupational carcinogen synergistic with cigarette smoke is asbestos, but other respiratory carcinogens reviewed include uranium, iron ores, nickel, arsenicals, vinyl chloride, halo ethers, nitrogen and sulfur mustards, and coke oven aerosols (23). Regardless of the magnitude of an environmental exposure, it is clear that smokers in any occupation are at greater risk for many diseases than are nonsmokers. It is also clear, however, that the hazardous industrial agents so far studied are mainly associated with male workers.

We address here two major shortcomings in the field of occupational medicine: (a) the scant attention paid to cigarette smoking in occupational studies of morbidity and mortality, and (b) the scant attention paid to women as an important component of the workforce. Since data are sorely lacking for a critical review of occupational health/smoking problems for women, we will highlight some features of both areas and suggest what data are needed in future epidemiologic studies upon which reasonable preventive measures can be based.

\section{WOMEN, TOBACCO, AND DISEASE}

Historically, sex ratios for tobacco-related diseases have been heavily weighted toward males. Differences in disease incidence rates between the sexes, however, have been diminishing during the past decade. Thus, since we are experiencing an expansion in both the size of the female labor force and the proportion of women who smoke, the health consequences of such behaviors deserve, and are receiving, increased attention. For example, it is reported that smokers experience more days of restricted activity than nonsmokers and that the annual number of work days lost because of cigarette smoking is higher for females than for males (22.6 and 19.4, respectively) (54). Since national surveys indicate that the majority of those women who choose to smoke are employed outside the home (33 vs $27 \%$ of housewives who smoke), it is likely that workdays lost due to smoking will increase in the future (55).

The smoking habits of women recently have gained attention in national surveys and epidemiologic research $(55,57,58,68,69)$. Unlike men, women, and particularly young women, are increasingly taking up the smoking habit $(58,68)$. Thus, estimating relative risks of developing certain cancers among smoking women has 
become the focus of a number of studies, as has determining the effect of smoking on pregnancy, rates of heart disease among women, and neonatal and perinatal morbidity.

In a recent study of a variety of tobacco-related cancers, relative risks for cancer of the lung, mouth and larynx, esophagus, and bladder were observed (69). Although the magnitude of risk is somewhat less for females than males, a dose-response relationship is apparent (Fig. 1). The decreased risk for women primarily reflects their preference for smoking filter cigarettes, and specifically the newer low-tar, filter cigarettes (68).

We also demonstrated that cessation of smoking leads to a lessening of risk, the magnitude of which depends on the number of years of cessation. Because historically, the smoking population has included considerably fewer women, the proportion of ex-smokers among women in any given sample is usually quite small. Nonetheless, as can be seen in Table 1, as years of ex-smoking increase, risk for
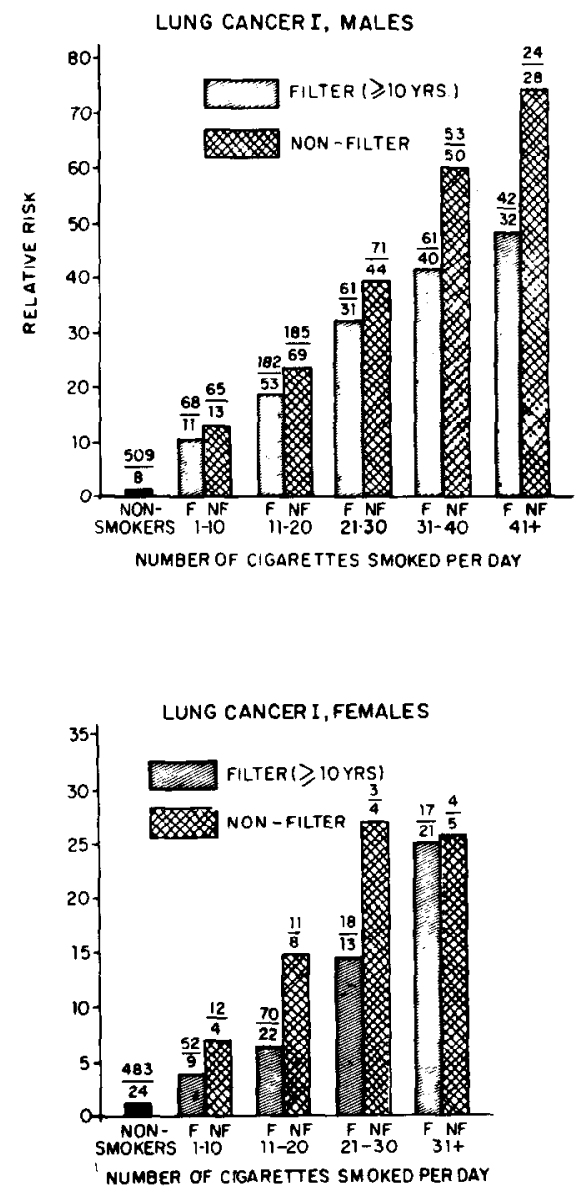

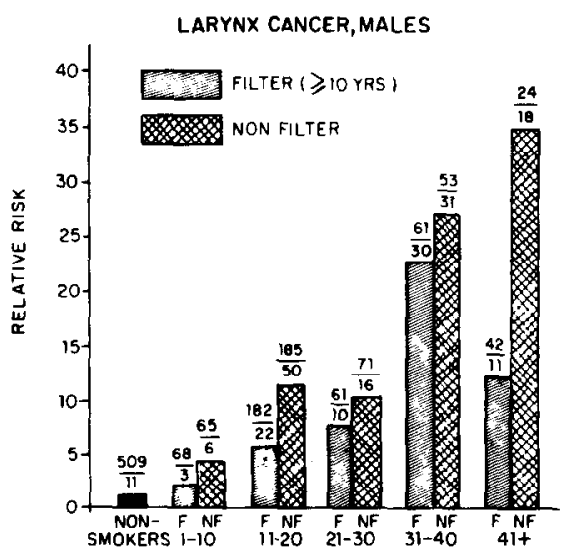

NUMBER OF CIGARETTES SMOKED PER OAY

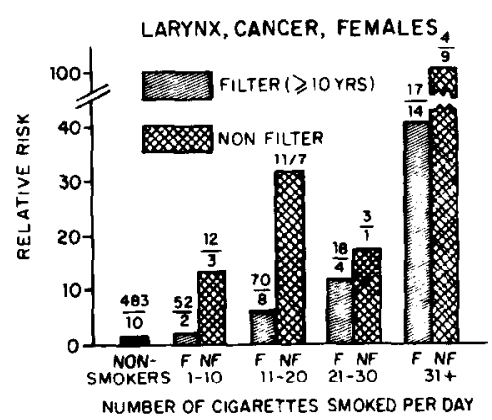

Fig. 1. Relative risk of lung (Kreyberg I) and larynx cancer for males and females by quantity and amount of cigarettes smoked (69). 


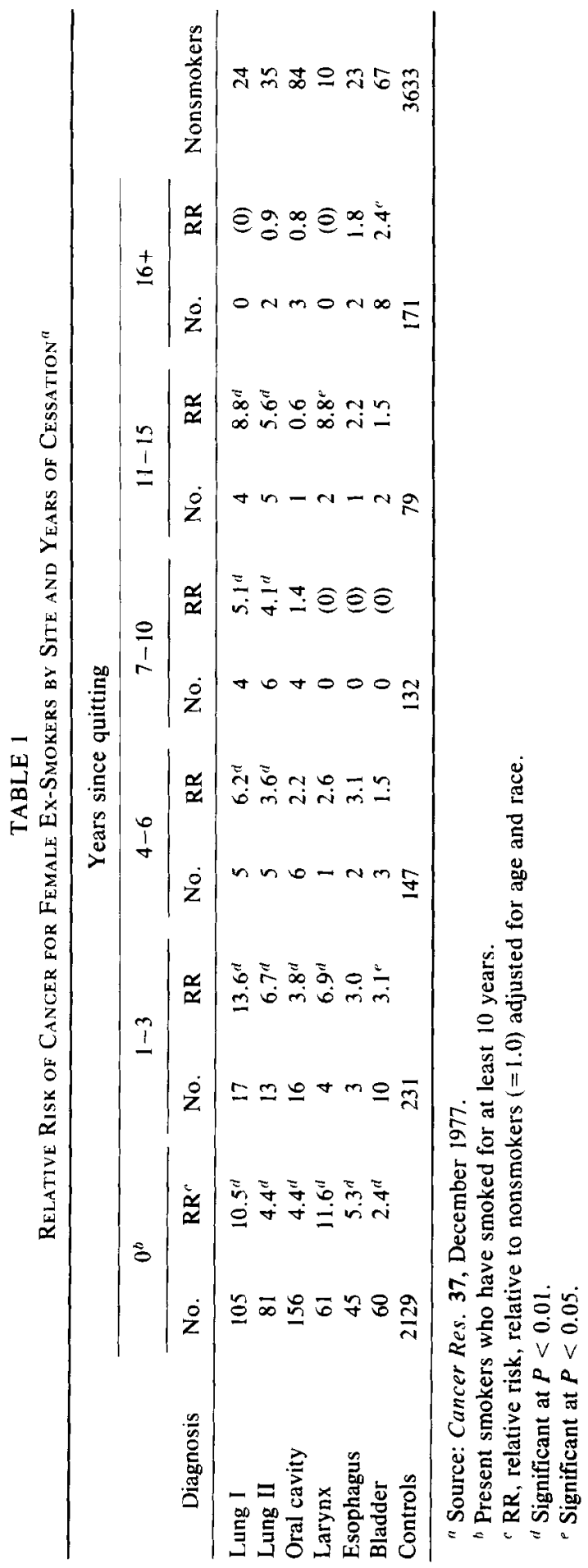


all six cancers studied decreases. As expected, this decreased risk parallels that found for males, but to a lesser degree.

Additional female health problems are anticipated because of the correlation between cigarette smoking and alcohol consumption. Alcohol appears to interact with cigarette smoke by promoting carcinogenesis in the larynx and upper alimentary tract $(66,67)$. Thus, as women increase their consumption of both tobacco and alcohol it is likely that their rates of oral cavity, esophageal, and laryngeal cancers among smokers will increase.

It is well-known that cigarette smoking is significantly associated with increased risk of cardiovascular diseases $(3,4,11,19,20,25,29,56)$. Because women do not share the same high incidence rates of ischemic heart disease and myocardial infarction (MI) as men, most of the research has concentrated on ways of identifying risk factors in males. Women, however, are known to share a number of CHD risks with men, most notably cigarette smoking, hypercholesteremia, and hypertension.

In studies by Bengtsson, significantly more women who had suffered an MI were smokers than those in a group in the general population; and among the smokers, the heart attack patients smoked more cigarettes per day than did the controls $(3,4)$. Further, it has been estimated that the risk of sudden death in white women who smoke is four times that of nonsmoking female controls $(11,29)$. Although additional study is in order, it is likely that the incidence of heart disease in women will increase as the current group of young women who smoke reaches the age for heart disease.

Since nearly one-third of women in the U.S. of child-bearing age smoke cigarettes, the influence of smoking on the incidence of birth defects and pregnancy complications has received considerable attention $(2,22,26,37,43,44,53)$. Not only are the infants born to mothers who smoke more likely to be underweight, but they usually encounter more bronchial infections, chest infections, and pneumonia than babies of nonsmoking mothers $(43,44)$. In addition, it has been reported that heavy smoking by the mother nearly doubles the infant's odds of dying within a month of birth, and the chances for a spontaneous abortion is increased in a woman who smokes during her pregnancy $(2,26,37)$. As women postpone childbirth because of career opportunities, it seems likely that the incidence of birth defects, pregnancy complications, premature birth, etc., will also increase.

In addition to the above, smoking is known to affect the body's ability to utilize Vitamin C, a fact which does not appear to be altered by a supplemental dose of this vitamin to the diet $(40,60)$. An already discovered consequence of this situation is that the milk of pregnant or lactating women who smoke has lower concentrations of Vitamin C (61). Thus, women who continue to smoke during pregnancy and the months of nursing have depleted levels of this vitamin to share with the developing or growing baby. Further, it has been shown that nicotine is excreted through the mother's milk and that the effects of this drug on the baby vary with the infant's age (41). Rowan has shown that smoking 10-20 cigarettes a day leaves 0.4 to $0.5 \mathrm{mg} /$ liter of nicotine in the milk of lactating women (42). Maternal smoking, therefore, can result in damage to the fetus, and the neonate, as well as to the 
mother. Such findings and their implications deserve a great deal more attention.

Women who smoke also appear to be at higher risk for cancer of the cervix (65). It is not known whether this relationship is a causal one or due to confounding by socioeconomic factors which relate both to smoking and cervical cancer. Although no evidence has been found for any relation between cigarette smoking and breast cancer, the discovery of nicotine in breast fluid $15 \mathrm{~min}$ after smoking should be further researched $(39,41,42)$.

Recognition of tobacco smoke as a cofactor in occupational cancers is increasing. One example is the excessive death rates (the majority from malignant neoplasms of the respiratory tract) that were found for workers involved in underground uranium mining $(10,27,30,46,47,62,63)$. When these data were adjusted for cigarette smoking, they demonstrated significantly higher risks for cancer development among the miners who smoked than among those who did not smoke (62). The causative agents in the atmosphere of mines have been identified as $\alpha$-particles, resulting from the decay of the short-lived radon daughters (10). Since the relation between cigarette "tar" and lung cancer risk is well-known, investigators conclude that there is a powerful synergistic effect resulting from combined cigarette smoking and exposure to radon daughters. Additionally, data extrapolated from animal studies indicate that a synergistic effect exists between benzo(a)pyrene (a constituent in tobacco smoke) and $\alpha$-radiation ( ${ }^{210} \mathrm{Po}$ ) exposure (31). As data accumulate, the possible additive or synergistic relation between these two exposures will be further defined.

It has been firmly established that various allergic lung reactions, mesothelioma of the pleura and peritoneum, and cancer of the lung (in combination with tobacco smoke) are causally related to asbestos dust exposure $(6,9,18,49,63)$. The joint effect of cigarette smoking and asbestos exposure has recently received increased attention $(5,21,35,36,50)$. It has been demonstrated that asbestos workers who smoke experience a significantly higher risk of bronchogenic cancer than nonsmokers and that the risk increases as cigarette consumption increases. The possibility that exposure to asbestos dust and cigarette smoke may be multiplicative, as well as additive, was suggested by the results of a study of asbestos workers in London $(5,35,36)$. Controlling for smoking habits, observed/expected rates of lung cancer in male smokers with high levels of asbestos exposure were found to be 22.5/9.9 and for females, 15.5/1.4. Short of insisting that all people quit the smoking habit, the most logical and prudent means for decreasing the risk of developing lung cancer for such workers is to prohibit smoking in and around asbestos mines, in particular, and to educate all employees, in general, about the benefits and methods of smoking cessation.

Further study is needed to document the possible cocarcinogenic action of tobacco smoke with various inorganic arsenicals on the respiratory tract. Available evidence suggests a relation, but more detailed smoking histories are necessary in order to evaluate the independent or synergistic effect of tobacco smoke and exposure to substances such as chromate, chloromethyl ethers, vinyl chloride, and coke oven emissions $(7,8,12,13,16,28,33,34,51,59)$.

Among the industrial carcinogens known to increase one's risk of developing bladder cancer are $\beta$-naphthylamine, benzidine, and 4-aminobiphenyl (23). Tobacco smoke contains certain of these amines (38), and since it also may "contain $N$ - 
nitrosamines which are metabolically activated to bladder carcinogenesis" (23), a powerful interactive effect may be produced by exposure to both. Again, the necessity of collecting additional data relative to exposure and tobacco usage is underscored before definitive conclusions can be drawn.

It is obvious that as the proportion of women employed in heavy industry increases, the problems listed above will begin to affect women also. Clearly, additional study is in order to uncover the specific relation between smoking and these and other occupational exposures. With the working woman's increased participation and visibility in these jobs, as well as her increased cigarette smoking, her representation in the numbers of people with an occupationally and/or tobacco-related disease will also increase.

\section{THE WOMEN WHO SMOKE}

Regrettably, there is some evidence that the profile of today's female smoker is indeed in agreement with the attractive image portrayed in advertising campaigns. That is, she is more likely to be young, well-educated and aspiring to a career. We present here some characteristics of female smokers ascertained from our ongoing epidemiological investigation of tobacco-related diseases. The data shown are based on approximately 7400 women and 7900 men interviewed as "controls" in our retrospective case-control study. (Controls are defined as those persons hospitalized with no previous or present history of a tobacco-related disease.) From this sample, a number of distinctions between smoking habits of males and females emerged (68).

As is apparent in Fig. 2, the majority of the women (54\%) are classified as
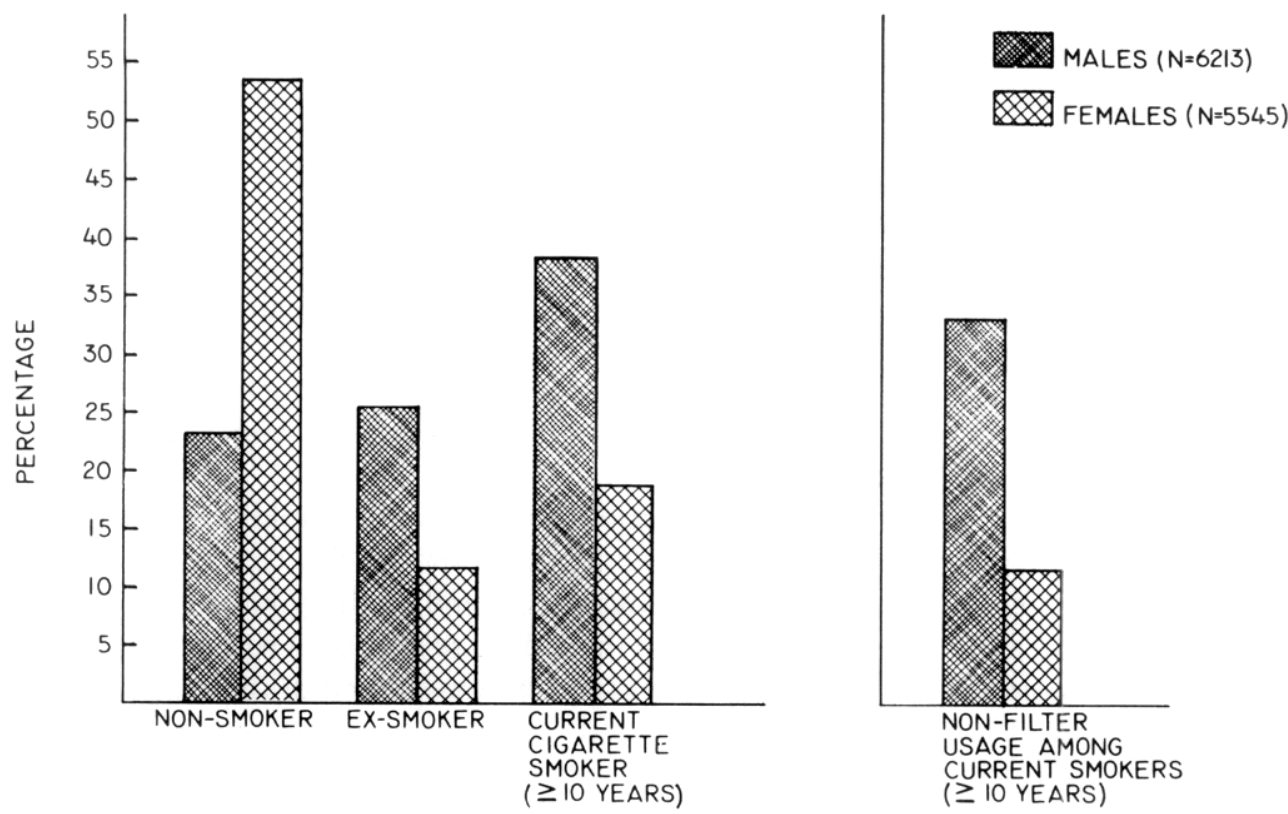

FIG. 2. Smoking habits for male and female controls (68). 


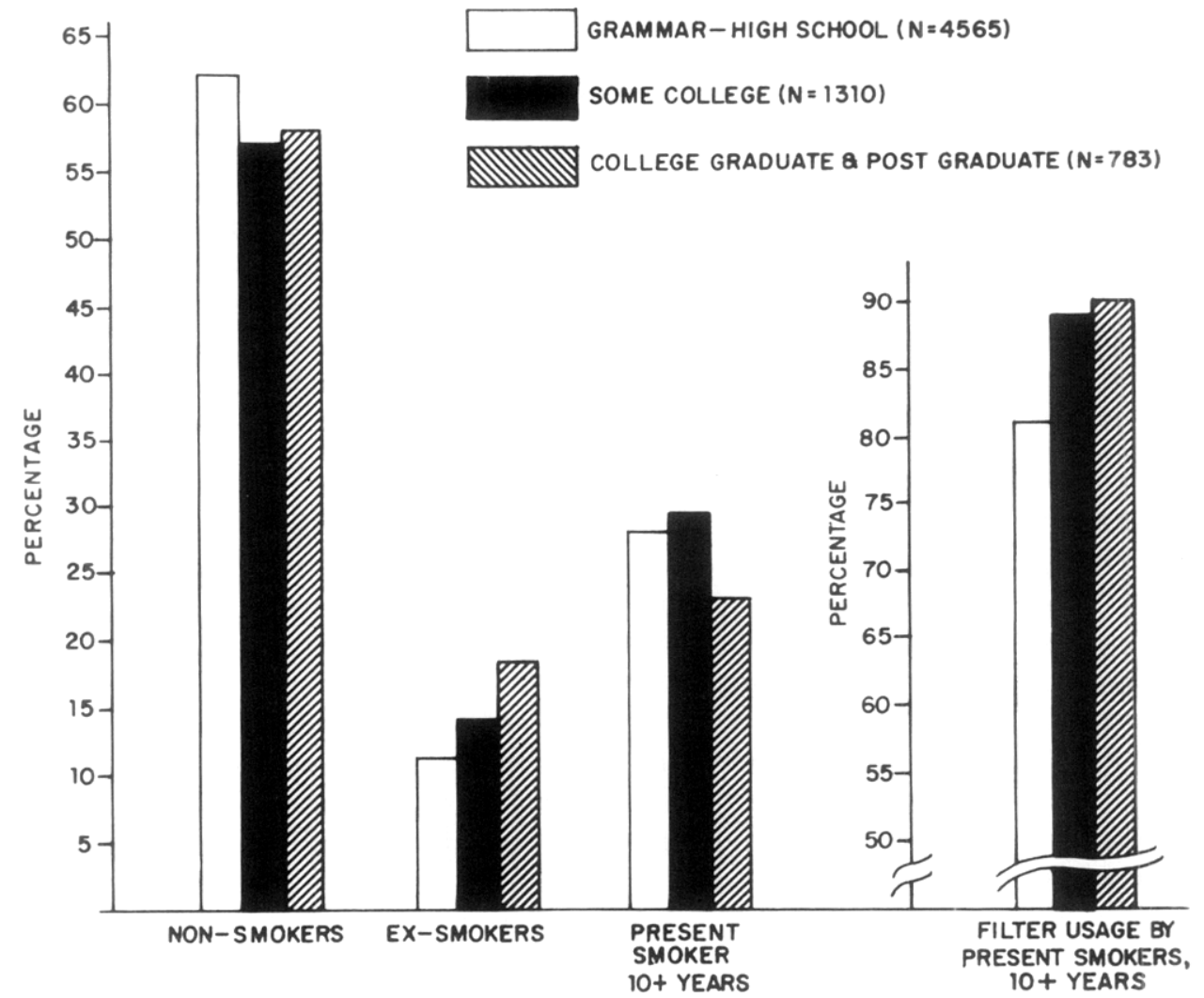

FIG. 3. Distribution of smoking habits of female controls (68).

"nonsmokers" (a proportion almost double that found among the males); among those women who do smoke, only $12 \%$ smoke nonfiltered cigarettes. However, twice as many males as females are "ex-smokers," which is a partial reflection of the larger pool of male smokers in the general population.

The influence that education exerts on the smoking habits of females and males in this control population is also apparent (Figs. 3 and 4). The highest proportions of nonsmokers and ex-smokers of both sexes are found among those who have either completed college or continued their education past the bachelors level. Of particular note is that nonfilter cigarette smoking decreases consistently with increased educational attainment.

Tables 2 and 3 present additional relationships between smoking and various demographic characteristics of females and males, respectively. Unlike the males, where the greatest proportion of nonsmokers is found in the youngest age category, more nonsmokers are represented in the older age groups in women. This fact is additional supportive evidence of the current national trend of increased smoking among young women $(55,58)$. The positive relationship between educational attainment and occupational status is also seen in these tables. For both sexes, average consumption appears to increase with higher occupational and education 


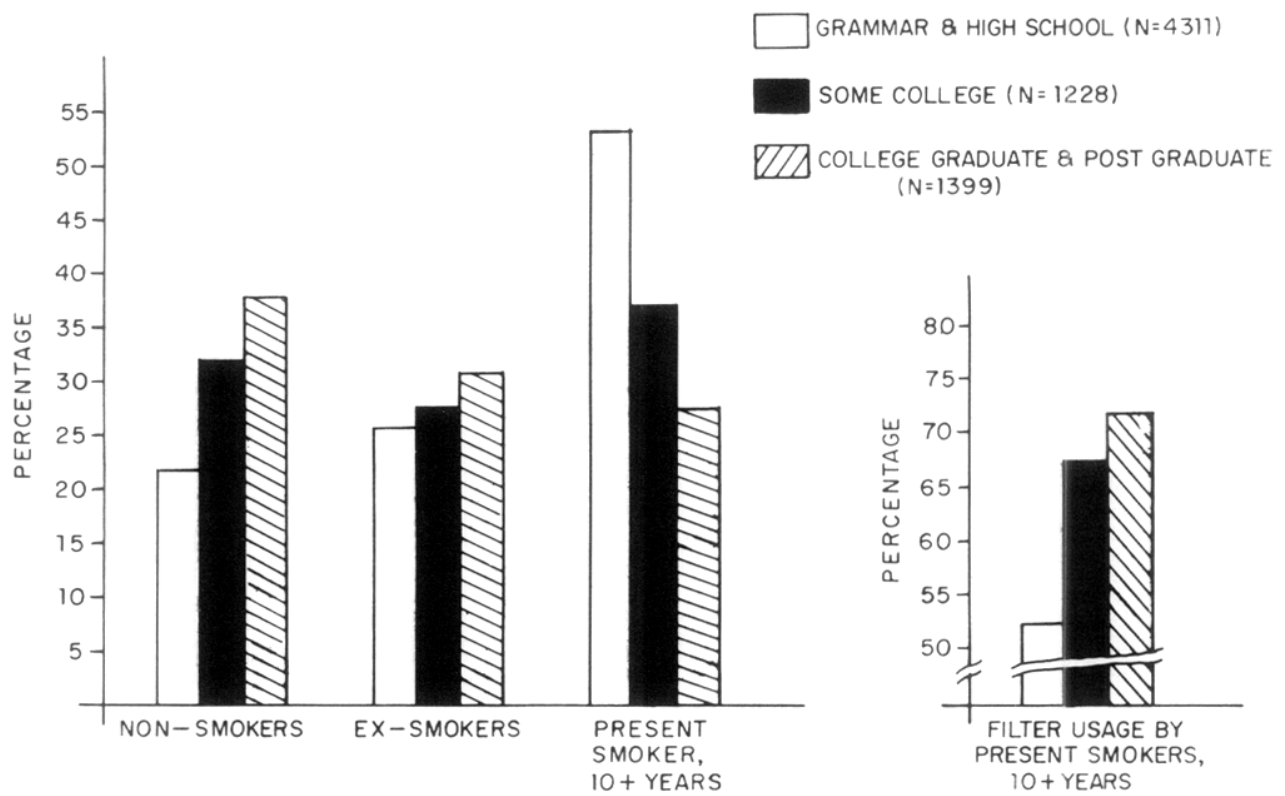

FIG. 4. Distribution of smoking habits of male controls (68).

attainment, a fact of increasing relevance as more women attain higher education and executive and professional positions. Although the differences are not as large in the female data as in the male sample, blacks of both sexes consistently have the lowest proportion of nonsmokers and the highest proportion of nonfilter smokers.

As previously indicated, lower rates of tobacco-related diseases are found among women, relative to men, even among life-long smokers of equal numbers of cigarettes. Two possible explanations exist: either women are histologically more resistant to these diseases than are men, or else, on the average, they smoke "less harmful" tobacco products such as low-tar cigarettes. Our data appear to favor the latter explanation. Figure 5 shows a dose--response curve for both men and women in which the dosage score is in milligrams of "tar" per day, averaged over the subjects' 15 most recent years of smoking. The two curves are statistically indistinguishable.

As seen in Table 4, across all smoking categories, women consistently began the smoking habit approximately 3 years later than men and smoked an average of five cigarettes a day fewer than their male counterparts. The smallest proportion of nonfilter smokers is found among the youngest women; this proportion increases successively with age. After age 40 , the proportion of women in each smoking category who consume more than 20 cigarettes per day decreases with increasing age. Average number of cigarettes consumed per day is greatest among women $30-39$. Thus, the younger women smoked more than the older women in this sample, a finding consistent with other studies that the smoking habits of young women are becoming more similar to those of men. 
TABLE 2

Percentage Distribution of Selectlo Demographic.

Characteristics by Tobacco Exposure

(FEMALE)

\begin{tabular}{|c|c|c|c|c|c|c|}
\hline & Nonsmokers & Exsmokers & $\begin{array}{c}\text { Filter } \\
\text { smokers }\end{array}$ & $\begin{array}{l}\text { Nonfilter } \\
\text { smokers }\end{array}$ & $\begin{array}{l}\text { Cigar/ } \\
\text { pipe }\end{array}$ & Total \\
\hline \multicolumn{7}{|l|}{ Race } \\
\hline White & 53.7 & 12.0 & 30.8 & 3.5 & 0.1 & $(5545)$ \\
\hline Black & 49.4 & 9.0 & 33.6 & 6.5 & 1.4 & (1428) \\
\hline Other & 67.6 & 5.1 & 23.8 & 2.8 & 0.8 & (472) \\
\hline Total & $(4009)$ & (816) & (2293) & (302) & (25) & (7445) \\
\hline \multicolumn{7}{|l|}{ Age } \\
\hline $20-29$ & 49.3 & 6.6 & 42.9 & 1.2 & - & (806) \\
\hline $30-39$ & 48.8 & 9.5 & 38.3 & 3.3 & 0.1 & $(1051)$ \\
\hline $40-49$ & 45.5 & 10.3 & 37.2 & 6.7 & 0.3 & (1559) \\
\hline $50-59$ & 48.6 & 12.8 & 33.1 & 5.0 & 0.5 & $(1783)$ \\
\hline $60-69$ & 62.2 & 13.8 & 20.2 & 3.3 & 0.5 & (1429) \\
\hline $70-89$ & 77.3 & 9.8 & 10.2 & 2.1 & 0.5 & (793) \\
\hline Total & (3989) & $(816)$ & $(2289)$ & (302) & (25) & $(7421)$ \\
\hline \multicolumn{7}{|l|}{ Education } \\
\hline Grammar/none & 62.7 & 8.8 & 22.5 & 4.8 & 1.2 & (1613) \\
\hline High school/trade & 51.5 & 10.3 & 33.5 & 4.7 & - & (3893) \\
\hline Some college & 49.3 & 12.1 & 36.3 & 2.3 & - & $(1082)$ \\
\hline College graduate & 53.3 & 16.0 & 28.0 & 2.6 & - & $(568)$ \\
\hline Postgraduate & 54.4 & 17.9 & 26.3 & 1.1 & 0.4 & (285) \\
\hline Total & $(4010)$ & (816) & (2293) & (302) & $(20)$ & (7441) \\
\hline \multicolumn{7}{|l|}{ Occupation } \\
\hline Professional & 53.4 & 11.8 & 33.7 & 0.8 & 0.3 & (380) \\
\hline Skilled & 47.5 & 12.4 & 36.8 & 3.2 & 0.1 & $(1460)$ \\
\hline Semiskilled & 51.6 & 8.5 & 36.6 & 2.9 & 0.5 & (446) \\
\hline Unskilled & 54.0 & 7.0 & 31.5 & 6.8 & 0.7 & (456) \\
\hline Retired & 51.6 & 12.1 & 31.1 & 4.7 & 0.6 & $(1361)$ \\
\hline Housewife & 58.0 & 10.6 & 26.9 & 4.2 & 0.3 & (3325) \\
\hline Total & $(4002)$ & $(814)$ & (2288) & (299) & $(25)$ & $(7428)$ \\
\hline
\end{tabular}

\section{THE WOMAN WHO WORKS}

With the possible exception of the acknowledgement that beauticians and nurses are frequently exposed to a variety of irritating substances $(17,32)$, data on female occupational exposures are limited. This is true despite the steady increase in the proportion of working women; current estimates are that women account for approximately $43 \%$ of the civilian labor force (54). Of these working women, the majority (39.3\%) are between the ages of 20 and 34 . This poses a number of serious problems not only for the employer but also the woman worker. The employer often must be coerced into providing additional monitoring or protective mechanisms to ensure the female workers' safety and to preclude potential medical costs associated with pregnancy complications or neonatal morbidity or mortality.

Although women have made substantial gains in the types of jobs open to them, they continue to be overrepresented in jobs such as nursery/primary school 
TABLE 3

Percentage Distribution of Selected Demographic

Characteristics by Tobacco Exposure

(MALE)

\begin{tabular}{|c|c|c|c|c|c|c|}
\hline & Nonsmokers & Exsmokers & $\begin{array}{c}\text { Filter } \\
\text { smokers }\end{array}$ & $\begin{array}{c}\text { Nonfilter } \\
\text { smokers }\end{array}$ & $\begin{array}{l}\text { Cigar/ } \\
\text { pipe }\end{array}$ & Total \\
\hline \multicolumn{7}{|l|}{ Race } \\
\hline White & 23.5 & 25.4 & 30.0 & 12.8 & 8.4 & (6213) \\
\hline Black & 17.7 & 15.7 & 35.1 & 23.8 & 7.8 & (1363) \\
\hline Other & 33.4 & 17.3 & 31.5 & 13.1 & 4.7 & (359) \\
\hline Total & (1823) & $(1851)$ & $(2451)$ & $(1166)$ & $(644)$ & (7935) \\
\hline \multicolumn{7}{|l|}{ Age } \\
\hline $20-29$ & 37.1 & 9.9 & 46.7 & 3.7 & 2.5 & (913) \\
\hline $30-39$ & 24.9 & 13.6 & 42.4 & 15.4 & 3.7 & $(865)$ \\
\hline $40-49$ & 20.1 & 18.8 & 36.9 & 19.2 & 5.0 & (1446) \\
\hline $50-59$ & 17.4 & 25.4 & 30.0 & 19.5 & 7.7 & (1973) \\
\hline $60-69$ & 20.2 & 32.0 & 22.6 & 13.9 & 11.3 & (1833) \\
\hline $70-89$ & 27.5 & 32.6 & 12.3 & 9.6 & 18.1 & (874) \\
\hline Total & $(1798)$ & $(1853)$ & $(2441)$ & (1167) & $(645)$ & (7904) \\
\hline \multicolumn{7}{|l|}{ Education } \\
\hline Grammar/none & 19.8 & 22.7 & 27.6 & 21.6 & 8.2 & (1813) \\
\hline High school/trade & 18.8 & 23.1 & 33.7 & 17.3 & 7.2 & (3262) \\
\hline Some college & 27.3 & 22.0 & 34.8 & 8.7 & 7.3 & $(1212)$ \\
\hline College graduate & 30.1 & 24.0 & 27.7 & 8.0 & 10.3 & (934) \\
\hline Postgraduate & 33.5 & 27.8 & 23.5 & 4.4 & 10.9 & (710) \\
\hline Total & $(1822)$ & (1851) & $(2488)$ & $(1166)$ & $(644)$ & (7931) \\
\hline \multicolumn{7}{|l|}{ Occupation } \\
\hline Professional & 29.2 & 25.8 & 28.5 & 5.7 & 10.9 & (1032) \\
\hline Skilled & 23.0 & 24.4 & 33.6 & 12.1 & 6.9 & (2414) \\
\hline Semiskilled & 18.1 & 17.4 & 40.5 & 19.5 & 4.6 & (1130) \\
\hline Unskilled & 18.9 & 16.7 & 33.8 & 24.2 & 6.4 & $(592)$ \\
\hline Retired/unemployed & 23.5 & 25.4 & 24.9 & 16.4 & 9.9 & (2744) \\
\hline Total & (1813) & (1851) & (2438) & (1165) & $(645)$ & (7912) \\
\hline
\end{tabular}

teachers, nurses, domestic workers, cashiers, waitresses, beauticians, secretaries, seamstresses, etc. (52). Whether due to physiological characteristics or social norms, women generally have been excluded from the ranks of fire-fighters, ditch diggers, blast furnace operators, carpenters, miners, plumbers, street pavers, heavy construction work, etc. Thus, by exclusion, women have not been directly exposed to a number of potent occupational hazards. Some attention has been paid, however, to the indirect exposure of family members to dust and residues of hazardous substances brought into the house by the working member of the household. Such exposures may not only cause skin irritations or allergies, but as in the case of asbestos that is carried into the home on clothes, more serious consequences, e.g., mesotheliomia, even from such indirect exposure, may result (1).

The toxic effects of most of the substances with which women frequently come into contact have not been sufficiently evaluated. Dr. J. Stellman has dealt with a number of the known reproductive hazards of occupational significance, such as 

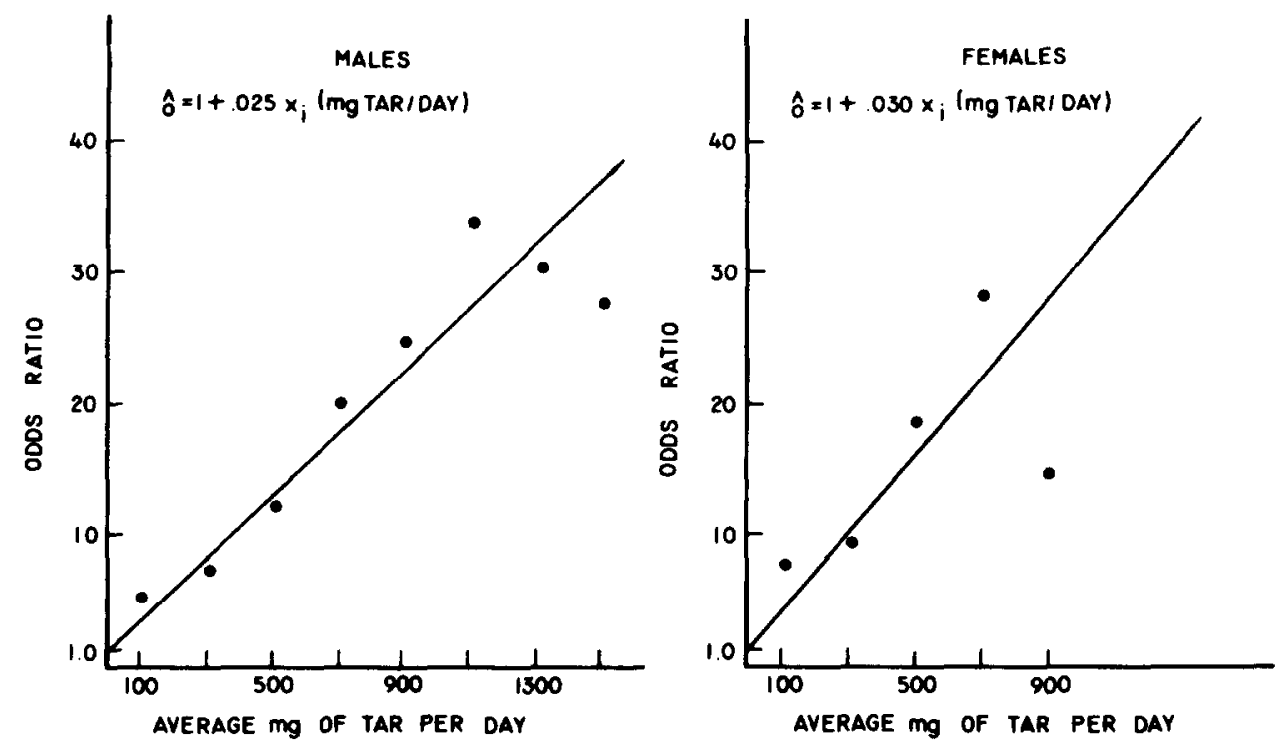

FIG. 5. Odds ratio estimates of relative risk of lung cancer as a function of average daily tar intake for males and females (Wynder, E. L.. and Stellman, S. D. Lung cancer in men and women in relation to cigarette tar. Submitted for publication).

$\mathrm{X}$-ray and radioisotope exposures to dental and medical technicians; infections frequently encountered by medical personnel/hospital workers; MOCA, BCME, and DES exposure associated with textile finishers, permanent-press workers, and histology technicians; some aniline dyes used by drug workers, dye workers, and some laboratory workers; etc. (52). Such a list will obviously lengthen as more women are employed in jobs hitherto considered male occupations. Nonetheless, in 1978 it is evident that a number of workplace hazards are experienced by a large group of women and are already identified as potentially harmful to the woman, as well as to a developing fetus.

Although most people consider office workers, the majority of whom are women, to be free from toxic exposures, a variety of health hazards are associated with such jobs. Office workers have been shown to be subject to substances such as benzene and toluene from rubber cement, cleaning compounds and solvents, methanol and ammonia from duplicating machines, air contaminants and muscle strains from long hours of sitting, standing, or reaching (52). The cumulative effect of each of these in a smoking and/or pregnant woman presents the possibility of serious health consequences, both in the present and the future.

Even if a woman is not a smoker or a drinker, as she enters the work force, undoubtedly she will become a "passive smoker," i.e., exposed to the sidestream smoke from her colleagues' cigarettes. Although estimates of health risks from passive smoking are quite difficult to make, measurements of sidestream smoke exposure have been made in various settings $(45,48)$. For instance, it has been reported that a person employed in a poorly ventilated bar, lounge, or nightclub can inhale the equivalent of 36 cigarettes during a normal 8-hr shift (45). The 
TABLE 4

Average Number of Cigarettes Smoked per Day by Selected Demographic Characteristics of Present Smoking Controls

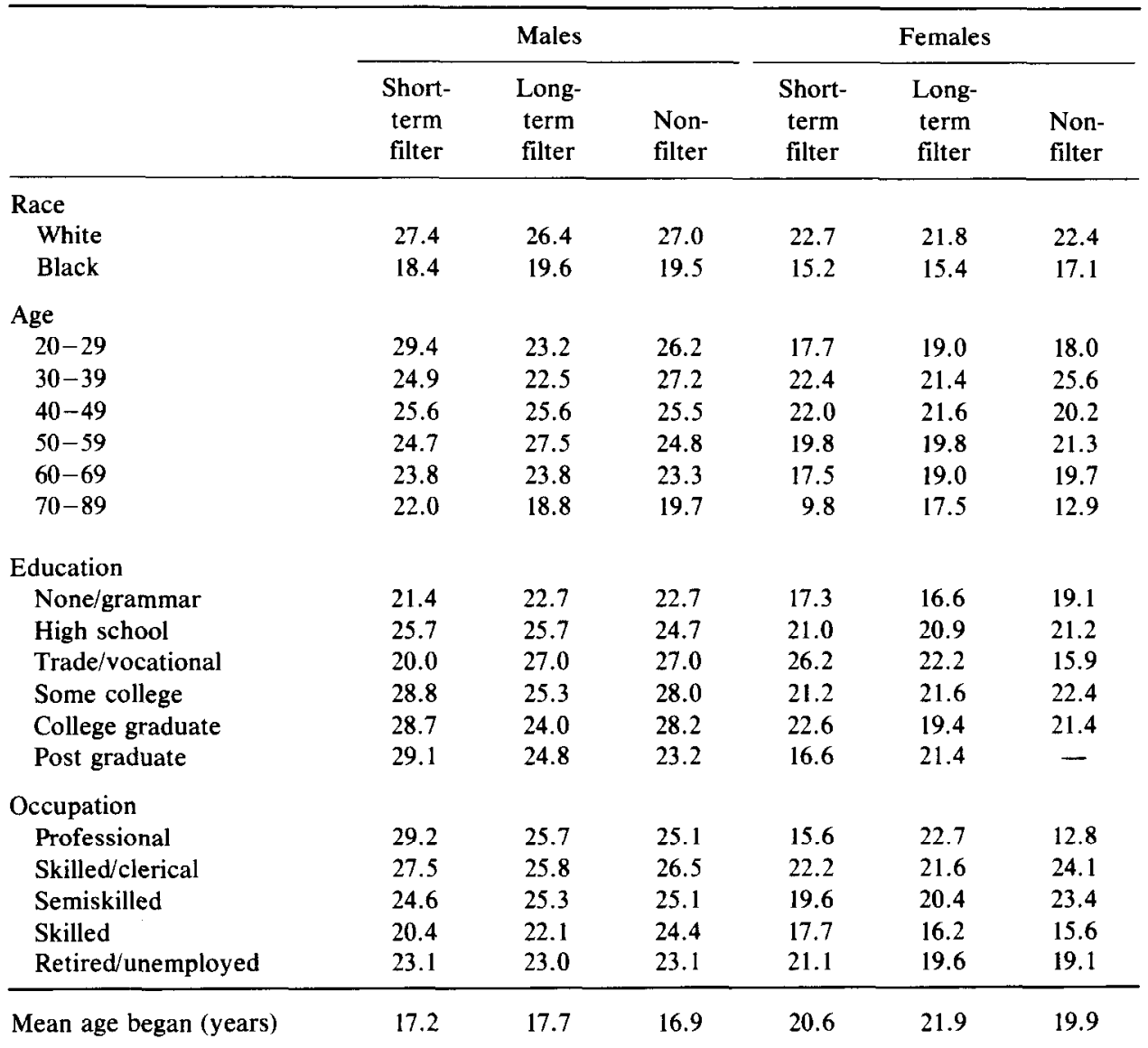

implications for bar maids, hostesses, entertainers and the like, not to mention the nonsmoking femalc executive who attends meetings in smoke-filled rooms, are obvious. Since reports indicate that such exposure can place extra strain on the heart patient who does not smoke, more epidemiologic research is warranted as is a reassessment of engineering requirements of enclosed spaces.

\section{CONCLUSION}

The health problems and needs of women, nearly half of the labor force in this country, must receive more attention. The Occupational Safety and Health Act of 1970 guarantees a safe and healthful workplace to every man and woman. Risks shared equally by men and women, it is hoped, will be evaluated and addressed by this law. But many occupational health problems which affect women as a group have not been adequately researched. The interaction between such potential exposures and cigarette smoking is impossible to assess at present. As more women enter jobs hitherto restricted to males while also continuing to take jobs 
traditionally assigned to females; as technology expands and potentially increases known hazards while it introduces new and unknown agents and products; as women continue to smoke more cigarettes and consume more alcohol; it is clear that the special health problems of women will require appropriate attention.

In addition, it is possible that rephrased research questions may be required to account for differences in physiology. For example, it is possible that biologically fixed characteristics of females (smaller lung capacity or size, fluctuations in the hormonal balance, lighter frames, etc.) and/or sex-specific behavior (e.g., use of oral contraceptives) will influence risk factors. Such a situation is cxemplified by the estimate that women over 40 who smoke and take "the Pill" experience an excess mortality rate from heart attack $(54.6$ per 100,000$)(24)$.

While the gaps in protection of rights must be filled in by education, organization, legal action, and political pressure, the gaps in knowledge can only be filled in by research. Future clinical and epidemiological studies must focus on women's occupations and must gather and analyze smoking data along with data on other exposures of interest.

\section{FUTURE EFFORTS}

It is obvious that additional research questions need to be addressed in order to better understand the mechanisms involved in occupational disease. Thus, a fuller

TABLE 5

Suggested Epidemiologic Variables to Be Included in Studies of Occupational Health among Women Workers

1. Tobacco usage

Type of tobacco: cigarette, cigar, pipe, snuff

Each brand: duration, amount per day, nonfilter, filter, low-tar filter status Inhalation

For ex-smokers, years since stopped

2. Alcohol

Type: beer, wine, liquor

Duration of regular drinking (years)

Frequency of drinking

Quantity consumed (per day or week)

3. Occupation history

Self

Spouse

4. Medications

Oral contraceptives (years used)

Estrogens (dosage, years taken)

5. Respiratory symptoms

cough (more than 3 months each year)

Sputum production

Shortness of Breath

6. Surgery and radiation history

Surgical procedures (years performed, site)

Radiation (frequency and type of treatment) 
evaluation of the hazards involved in various work settings will not only include monitoring the work site environment, expanding employee medical programs, and chemical analyses but will also be supplemented with epidemiologic data. The role played by physiologic and lifestyle variables in occupational health will become increasingly evident as these variables become a routine part of occupational health studies. As women contribute greater numbers to the labor force, sex-specific questions such as history of hysterectomy or estrogen usage will also have to be addressed.

In an effort to stimulate interest in the type of questions we feel should be incorporated into future investigations, Table 5 presents six variables of obvious epidemiologic relevance. While the needs of particular studies will dictate appropriate combinations of these variables, as a minimum requirement, extensive tobacco histories are essential in order to determine whether an exposure is an independent hazard or, whether in combination with other variables, it increases an employee's risk of developing disease.

\section{REFERENCES}

1. Anderson, H. A., Selikoff, I. J., Telis, R., et al. Asbestos-related disease from household exposure to occupational dusts. Presented at the American Conference of Chest Physicians, New Orleans, October 24, 1974.

2. Anonymous. Cigarette smoking and spontaneous abortion. Brit. Med. J. 6108, 259-260 (1978).

3. Bengtsson, C. Prevalence of multiple risk factors for ischaemic heart disease in women with and without known ischaemic heart disease. Acta Med. Scand. Suppl. 549, 97-105 (1973).

4. Bengtsson, C. Smoking habits in a population sample of women and in women with ischaemic heart disease. Acta Med. Scand. Suppl. 549, 60-64 (1973).

5. Berry, G., Newhouse, M. L., and Turok, M. Combined effect of asbestos exposure and smoking on mortality from lung cancer in factory workers. Lancet 2, 476-479 (1972).

6. Demy, N. G. Asbestosis. JAMA 175, 530 (1961).

7. Doll, R. Cancer of the lung and nose in nickel workers. Brit. J. Ind. Med. 15, 217-223 (1958).

8. Doll, R. Occupational lung cancer: A review. Brit. J. Ind. Med. 16, 181-190 (1959).

9. Doll, R. Mortality from lung cancer in asbestos workers. Brit. J. Ind. Med. 12, 81-86 (1955).

10. Donaldson, A. W. The epidemiology of lung cancer among uranium miners. Health Phys. 16, $563-569$ (1969).

11. Epstein, F. H. Some uses of prospective observations in the Tecumseh Community Health Study. Proc. Roy. Soc. Med. 60, 4-8 (1967).

12. Figueroa, W. G., Raszkowski, R., and Weiss, W. Lung cancer in chloromethylmethyl ether workers. New Engl. J. Med. 288, 1096-1097 (1973).

13. Fisher, R. S., and Riekert, P. W. Lung cancer in chromate workers. Amer. J. Pathol. 35,699 (1959).

14. Forum. Occupationally-induced diseases. (P. Shubik, Guest Editor) Prev. Med. 5, 226-315 (1976).

15. Friedman, G. D., Sieglaub, A. B., and Seltzer, C. C. Cigarette smoking and exposure to occupational hazards. Amer. J. Epidemiol. 98(3), 175-183 (1973).

16. Gafafer, W. M. Health of workers in chromate industry. U.S. Pub. Health Serv. Publ. 192 (1953).

17. Garfinkel, J., Selvin, S., and Brown, S. M. Possible increased risk of lung cancer among beauticians. J. Nat. Cancer Inst. 58(1), 141-143 (1977).

18. Gloyne, S. R. The morbid anatomy and histology of asbestos. Tubercle 14, 445-447 (1933).

19. Hammond, E. C. Smoking in relation to the death rates of one million men and women. Nat. Cancer Inst. Monogr. 19, 127-204 (1966).

20. Hammond, E. C., and Garfinkel, L. Coronary heart disease, stroke and aortic aneurysm: Factors in the etiology. Arch. Environ. Health 19, 167-182 (1969).

21. Hammond, E. C., and Selikoff, I. J. Relation of cigarette smoking to risk of death of asbestosis disease among insulation workers in the U.S. Int. Agency Res. Cancer Sci. Publ. 8, 312-317 (1973). 
22. Harlop, S., and Davies, A. M. Infant admission to hospitals and maternal smoking. Lancet 1, $1387-1388$ (1974).

23. Hoffmann, D., and Wynder, E. L. Smoking and occupational cancers. Prev. Med. 5, 245-261 (1976).

24. Jain, A. K. Mortality risk associated with the use of oral contraceptives. Stud. Fam. Plann. 8, 50-54 (1977).

25. Kannel, W. B., Castelli, W. P., and McNamara, P. M. Cigarette smoking and risk of coronary heart disease: Epidemiologic clues to pathogeneses. The Framingham Study. In "Towards a Less Harmful Cigarette." Nat. Cancer Inst. Monogr. 28 (1968).

26. Kline, A., Stein, Z. A., Sussex, M., and Warburton, D. Smoking: A risk factor for spontaneous abortion. New Engl. J. Med. 297, 793-796 (1977).

27. Kreyberg, L. Nonsmokers and the geographic pathology of lung cancer. In "The Lung" (C. A. Liebow and D. E. Smith, eds.), pp. 273-283. Williams and Wilkins, Baltimore, Maryland, 1968.

28. Langard, S., and Norseth, T. A cohort study of bronchial carcinogenesis in workers producing chromate pigments. Brit. J. Ind. Med. 32, 62-65 (1975).

29. Lough, J. Cigarette smoking, coronary heart disease and sudden death. Canad. Med. Assoc. J. 114, $919-921$ (1975).

30. Lundin, F. E., Jr., Lloyd, J. W., Smith, E. M., Archer, V. E., and Holaday, D. A. Mortality of uranium miners in relation to radiation exposure, hard-rock mining and cigarette smoking, 1950 through September 1967. Health Phys. 16, $571-578$ (1969).

31. McGandy, R. B., Kennedy, A. R., 'Terzaghi, M., and Little, J. B. Experimental respiratory carcinogenesis: Interaction between $\alpha$-radiation and benzo(a)pyrene in the hamster, in "Experimental Lung Cancer: Carcinogenesis and Bioassays"' (E. Karbe and J. F. Pack, eds.), pp. 485-491. Springer-Verlag, New York, 1974.

32. Menck, H. R., Pike, M. C., Henderson, B. E., and Jink, J. S. Lung cancer among beauticians and other female workers. J. Nat. Cancer Inst. 59, 1423-1425 (1977).

33. National Institute for Occupational Safety and Health. Chemicals suspected in six cases of lung cancer. Occup. Health Lett. 2, 6 (1972).

34. Nelson, N. Carcinogenicity of halo-ethers. New Engl. J. Med. 288, 1123-1124 (1973).

35. Newhouse, M. L. Cancer among workers in the asbestos textile industry. Int. Agency Res. Cancer Sci. Publ. 8, 203-208 (1973).

36. Newhouse, M. L., Berry, G., Wagoner, J. G., and Turok, M. E. A study of the mortality of female asbestos workers. Brit. J. Ind. Med. 26, 294-301 (1969).

37. O'Lane, J. M. Some fatal effects of maternal cigarette smoking. Obstet. Gynecol. 22, 181-184 (1965).

38. Pailer, M., Huebsch. W. J., and Kuhn, H. Untersuchung der aliphatischen und aromatischen primaren und sekundaren Amine des Zigarettenrauches mit Hilfer der Gaschronatographie und Massenspektrometrie. Fachliche Mitt. Oesterr. Tabakregie 7, 109-118 (1967).

39. Petrakis, N. L., Gruenke, L. D., Beelen, T. C., Castagnoli, N., and Craig, J. C. Nicotine in breast fluid of non-lactating women. Science 199, 303-305 (1978).

40. Pelletier, O. Cigarette smoking and vitamin C. Nutr. Today 5, 12-15 (1970).

41. Richer, C., and Guidirelli, J. F. Excretion of drugs in human milk. Rev. Med. 17, 1149-1157 (1976).

42. Rowan, J. J. Excretion of drugs in milk. Pharm. J. 217, 184-186 (1976).

43. Rush, D. Examination of the relationship between birthweight, cigarette smoking during pregnancy and maternal weight gain. J. Obstet. Gynec. Brit. Commonw. 81, 746-752 (1974).

44. Rush, D., and Kass, E. H. Maternal smoking: A reassessment of the association with perinatal mortality with other risk factors. Amer. J. Epidemiol. 96, 183-196 (1972).

45. Russell, M. A., Cole, P. V., and Brown, E. Absorption by nonsmokers of carbon monoxide from air polluted by tobacco smoke. Lancet 1, 576-579 (1973).

46. Saccomanno, G. U.S. Congressional Hearings before the Subcommittee on Research, Development and Radiation of the Joint Committee on Atomic Energy. 91st Congress, First Session on Radiation Standards for Uranium Mining, March 17-18, 302. U.S. Government Printing Office, Washington, D.C., 1969. 
47. Saccomanno, G., Archer, V. E., Saunders, R. P., James, L. A., and Becker, P. A. Lung cancer of uranium miners of the Colorado Plateau. Health Phys. 10, 1195-1201 (1964).

48. Schmeltz, I., Hoffmann, D., and Wynder, E. L. The influence of tobacco smoke on indoor atmospheres: I. An overview. Prev. Med. 4, 66-82 (1975).

49. Selikoff, I. J., Churg, J., and Hammond, E. C. Asbestos exposure, smoking and neoplasia. J. A. M. A. 188, 22-26 (1964).

50. Selikoff, I. J., Hammond, E. C., and Churg, J. Asbestos exposure, smoking and neoplasia. J. A. M. A. 204, 106-110 (1968).

51. Shubik, P. Medical iatrogenic cancer, in "Environment and Cancer," pp. 142-156. Williams and Wilkins, Baltimore, Maryland, 1972.

52. Stellman, J. M. "Women's Work, Women's Health." Pantheon Books, New York, 1977.

53. Underwood, P. B., Hester, L. L., Lafitee, T., Jr., and Gregg, K. V. The relationship of smoking to the outcome of pregnancy. Amer. J. Obstet. Gynecol. 91, 270-276 (1965).

54. U.S. Bureau of the Census. "Statistical Abstract of the United States: 1976," 97th ed. Washington, D.C., 1976.

55. U.S. Department of Health, Education, and Welfare. "Adult Use of Tobacco: 1975." Center for Disease Control, Atlanta, Georgia, 1976.

56. U.S. Department of Health, Education, and Welfare. "Smoking and Health: Report of the Advisory Committee to the Surgeon General of the Public Health Service." Public Health Service Publ. No. 1103. Washington, D.C., 1964.

57. U.S. Department of Health, Education, and Welfare, "The Health Consequences of Smoking." Center for Disease Control, Atlanta, Georgia, 1974, 1975, 1976, 1977.

58. U.S. Department of Health, Education, and Welfare. "The Smoking Digest." National Cancer Institute, Bethesda, Maryland, 1977.

59. U.S. Public Health Service. "Survey of Compounds Which Have Been Tested for Carcinogenic Activity," No. 149 (1951); Suppl. 1 (1957); Suppl. 2 (1969); DHEW (N. I. H.) $72-35$ (1972); DHEW (N. I. H.) 73-35, Sect. I. and Sect. II. (1973); DHEW (N. I. H.) 74-435 (1974).

60. Venulet, F. Consequences of vitamin $\mathrm{C}$ deficiency in smokers. Pol. Arch. Med. Wewn. 26, $393-402$ (1956).

61. Venulet, F., and Lausz, H. Influence of tobacco smoke on ascorbic acid content in mother's milk. Acta Phys. Pol. 4, 351-356 (1954).

62. Wagoner, J. K., Archer, V. E., Carrol, B. E., Holaday, D. A., and Lloyd, J. W. Cancer mortality patterns among U.S. uranium miners and millers, 1950-1962. J. Nat. Cancer Inst. 34, 787-801 (1964).

63. Wagoner, J. K., Miller, R. W., Lundin, F. E., Jr., Fraumeni, F. J. Jr., and Haij, M. E. Unusual cancer mortality among a group of underground metal miners. New Engl. J. Med. 269, 284-289 (1963).

64. Webster, I. Malignancy in relation to crocidolite and amosite. Int. Agency Cancer Res. Sci. Publ. 8, 195-198 (1973).

65. Williams, R. R., and Horm, J. W. Association of cancer sites with tobacco and alcohol consumption and socioeconomic status of patients: Interview study from the Third National Cancer Survey. J. Nat. Cancer Inst. 58, 525-547 (1977).

66. Wynder, E. L., Bross, I. D. J., and Day, E. A study of environmental factors in cancer of the larynx. Cancer 9, 86-110 (1956).

67. Wynder, E. L., Covey, L. S., Mabuchi, K., and Mushinski, M. H. Environmental factors in cancer of the larynx: A second look. Cancer 38, 1591-1601 (1976).

68. Wynder, E. L., and Mushinski, M. H. Epidemiology of tobacco usage among a hospital-based control population. In preparation.

69. Wynder, E. L., and Stellman, S. D. Comparative epidemiology of tobacco-related cancers. Cancer Res. 37, 4608-4622 (1977). 